\title{
Establishing a Restoration Narrative
}

In his article, "Ecological Restoration and Re-Understanding Ecological Time," Tom Simpson argues that restorationists should use narratives, rather than succession theory, to model and describe the "complex historical object" we have come to call an ecosystem. Like environmental historian William Cronon, Simpson asserts that places, landscapes, and ecosystems become knowable to us through the stories we tell about them. However, Simpson is careful to make the point that such stories should be embodied with "process-based science" so as to fully empower the narrative with as much meaning as possible. While I'm not going to explore Simpson's idea here, I think it serves as a good catalyst for a discussion about the role narratives play in establishing identities for individuals and more importantly for the movement and practice we know as ecological restoration.

Narrative or story-telling is, of course, as old as human language itself. Whether it pre-dates other personally and culturally identifying activities such as song, dance, painting, and toolmaking is not important. What is significant is the power of narrative to integrate these and other lived experiences and thereby capture the essence of an event or series of events, and, ultimately, to give identity and purpose to a person, village, or culture.

Numerous scholars have studied the role of narrative and identity. Perhaps the most notable is the French philosopher Paul Ricoeur, whose three-volume set, Time and Narrative (English translations, 1984, 1985, 1988, University of Chicago Press), explores the role of narrative in fiction, history, and identity. Key to his ideas about narrative and identity is Ricoeur's insistence that the analysis of narrative is deeper than a simple Cartesian study of a text or a speech. It requires a "hermeneutic" analysis that locates the narrative in a relationship with the lived experience. For Ricoeur, this involves a hermeneutic circle of narrative and action that shares a threefold process of prefiguration (lived experience), configuration (narrative informed by lived experience), and refiguration (practical action informed by narrative). The constant interaction of these activities provides the individual or organization with a meaningful identity, a framework (a plot or story) for seeing how their lives intertwine with others, and a similar context for judging the ethics of their actions and the actions of others within the narrative. Together this comprises what Ricoeur calls a narrative identity.

Narratives also have the potential to be flexible and dynamic. Certainly there is much evidence that they can stay roughly the same for generations, or can even migrate to other continents as the West African trickster tales of bouki and leuk did, becoming the Uncle Remus stories of the southern United States. Some may be lost, especially when languages and cultural diversity are threatened with extinction. They may and typically do change when a dramatic event or an exceptionally gifted and/or powerful individual causes them to do so.

So, what about establishing a narrative for ecological restoration? Frankly, I think it has been underway for several decades, certainly within the pages of this and other journals; in books by Bill Jordan, Eric Higgs, Freeman House and many others; at conferences; at work parties; and in offices and pickup trucks. I've been privileged to observe and participate in this narrative for nearly twenty years, and here are a few of my considered thoughts. First, I could not agree more with Tom Simpson that we are revolutionaries whose language still carries the baggage of the past. Many of us (and many of the organizations we work for or with) are, like Br'er Rabbit, stuck to that tar baby of the resourcebased, conservation-era narrative and we can't seem to shake loose. It's important that we understand this because, as cognitive scientist George Lakoff (Moral Politics: How Liberals and Conservatives Think, 1996) points out, language shapes how we think. Using the language of a resource manager from the pre-Earth Day era is only going to trap us in that stage of our conservation efforts. Second, it seems to me that there remains no agreed upon narrative that describes an authentic restoration project, despite the fact that SER International has provided us with a definition of ecological restoration and a Primer to further explain its various aspects. We need to recognize that various scales of our restoration narrative work against us here-and that the broadscale Primer can only hope to capture the essence of the narratives we use in describing our local restoration efforts. That is not to say that the Primer is set in stone. It remains, like any good narrative, open to the hermeneutic circle of lived experience and interpretation. Finally, I sense that we are making some strides in reaching out to the people affected by our restoration narrative (see Marilyn Marler's article in this issue) and I want to applaud those efforts and encourage others to make similar attempts to bring our story to those who are seeking a beneficial way to reconnect with the place they inhabit.

Dave Egan 